\title{
A rare cause of gastric malignancy: Burkitt's lymphoma
}

\begin{abstract}
A 33-year-old man presented with a 1-week history of nausea, vomiting, and abdominal distension. Initial laboratory tests were significant for white blood cell count $\left(12 \times 10^{9} / \mathrm{L}\right)$, creatinine $(1.4 \mathrm{mg} / \mathrm{dL})$, and lactic acid dehydrogenase (2014U/L). Computed tomography scan showed severe thickening of the gastric body, ascites, and peritoneal induration ( $\mathbf{F i g} \mathbf{1} \mathbf{a}$ ). Based on these findings the patient underwent esophagogastroduodenoscopy, which revealed diffusely ulcerated mucosa involving the majority of the gastric body ( Fig.1b). Endoscopic ultrasound (EUS) demonstrated gastric wall thickening of up to $50 \mathrm{~mm}$ ( Fig. 1 c). Mucosal biopsies and fine-needle aspiration (FNA) of the gastric wall were performed. Epstein-Barr virus and HIV serology were negative, whereas Helicobacter pylori serology was positive.
\end{abstract}

Flow cytometry and cytologic examination of the FNA specimen demonstrated monotonous atypical CD10-positive B-cells with immunohistochemical stains positive for BCL-6 and C-MYC ( $\bullet$ Fig. 1 d-f) consistent with a diagnosis of Burkitt's lymphoma. Chemotherapy was initiated with the R-CHOP regimen as well as $H$. pylori eradication therapy.

Burkitt's lymphoma is a rare cause of B-cell non-Hodgkin lymphoma with an aggressive clinical course. Its sporadic variant frequently presents as extranodal disease with the gastrointestinal tract being the leading site. The terminal ileum has been reported as the most common site of gastrointestinal involvement [1]. Patients with gastrointestinal Burkitt's lymphoma may present with abdominal pain and distension, bleeding or intestinal obstruction. Endoscopy and EUS with FNA are the most important modalities to confirm the diagnosis. In comparison with mucosa-associated lymphoid tissue lymphomas, there are only isolated reports showing Burkitt's lymphoma remission after $H$. pylori eradication [2]. Patients with Burkitt's lymphoma localized to the stomach have better survival than those with non-gastric involvement [3]. Burkitt's lymphoma of the stomach is rare and can be difficult to diagnose. It should be considered as a differential diagnosis when gastric wall thickening is found on imaging. EUS has an increasingly recognized role in the timely diagnosis of this condition.

Endoscopy_UCTN_Code_CCL_1AB_2AD_3AB

Competing interests: N.J.S. is a consultant for Cook Medical and Covidien Inc. Other authors have no conflicts to disclose. lliana Doycheva1,2, Stacy Tanner², Delu Zhou ${ }^{3}$, N. Jewel Samadder ${ }^{1,2}$

${ }^{1}$ Department of Gastroenterology, Huntsman Cancer Institute and University of Utah, Salt Lake City, Utah, USA

${ }^{2}$ Department of Internal Medicine, Huntsman Cancer Institute and University of Utah, Salt Lake City, Utah, USA

${ }^{3}$ Department of Pathology, Huntsman Cancer Institute and University of Utah, Salt Lake City, Utah, USA

\section{References}

1 Jang SJ, Yoon DH, Kim S et al. A unique pattern of extranodal involvement in Korean adults with sporadic Burkitt lymphoma: a single center experience. Ann Hematol 2012; 91: 1917-1922

2 Baumgaertner I, Copie-Bergman C, Levy M et al. Complete remission of gastric Burkitt's lymphoma after eradication of Helicobacter pylori. World J Gastroenterol 2009; 15: 5746-5750

3 Park YH, Kim WS, Kang HJ et al. Gastric Burkitt lymphoma is a distinct type that has superior outcomes to other types of Burkitt lymphoma/leukemia. Ann Hematol 2006; 85: $285-290$

\section{Bibliography}

Dol http://dx.doi.org/

10.1055/s-0033-1358926

Endoscopy 2013; 45: E432-E433

(c) Georg Thieme Verlag KG

Stuttgart · New York

ISSN 0013-726X

\author{
Corresponding author \\ N. Jewel Samadder, MD, MSc \\ Huntsman Cancer Institute \\ 2000 Circle of Hope \\ Salt Lake City \\ UT 84112 \\ USA \\ Fax: +1-801-581-7476 \\ jewel.samadder@hsc.utah.edu
}

- Fig.1a-f See following page. 

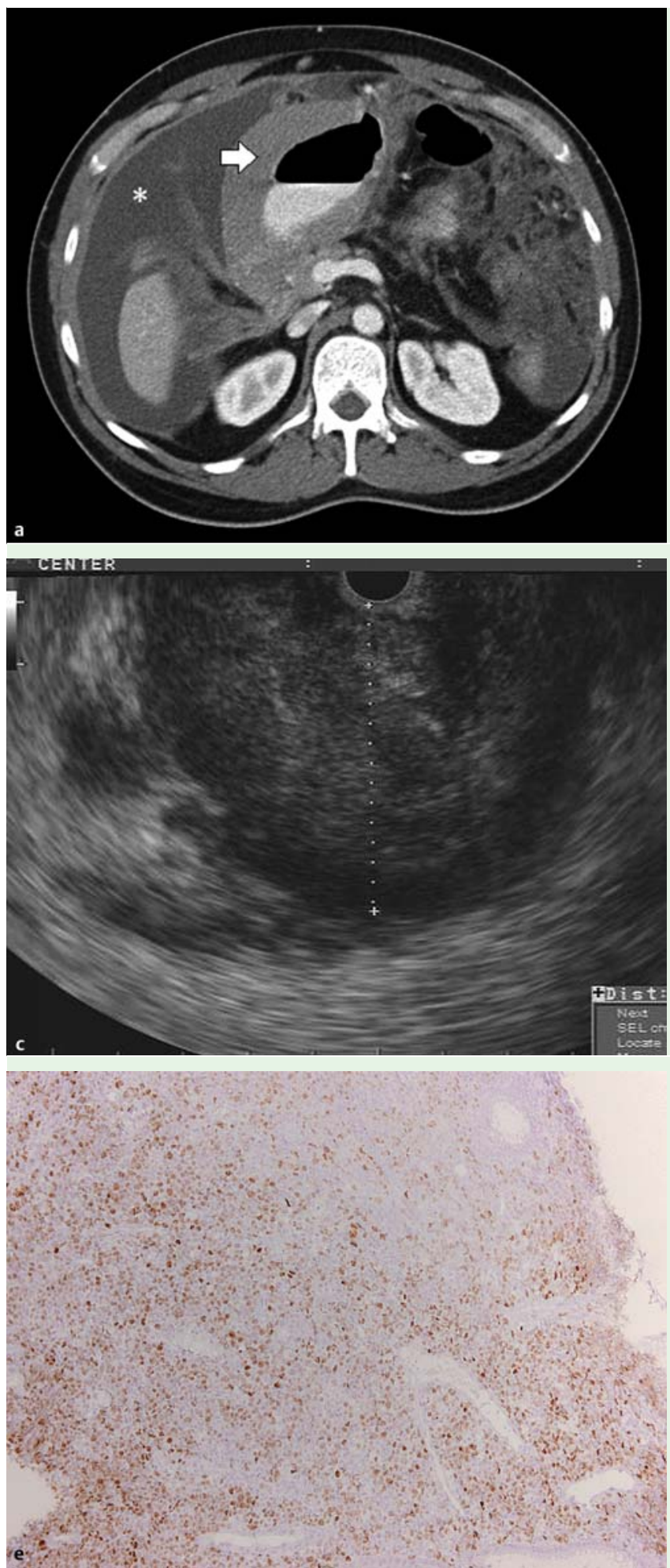

Fig. 1 Investigations in a patient with Burkitt's lymphoma. a Computed tomography scan findings of gastric wall thickening (arrow) and ascites (asterisk). b Esophagogastroduodenoscopy findings of ulcerated mucosa in the gastric body and antrum. $\mathbf{c}$ Endosonographic findings of thickened gas-
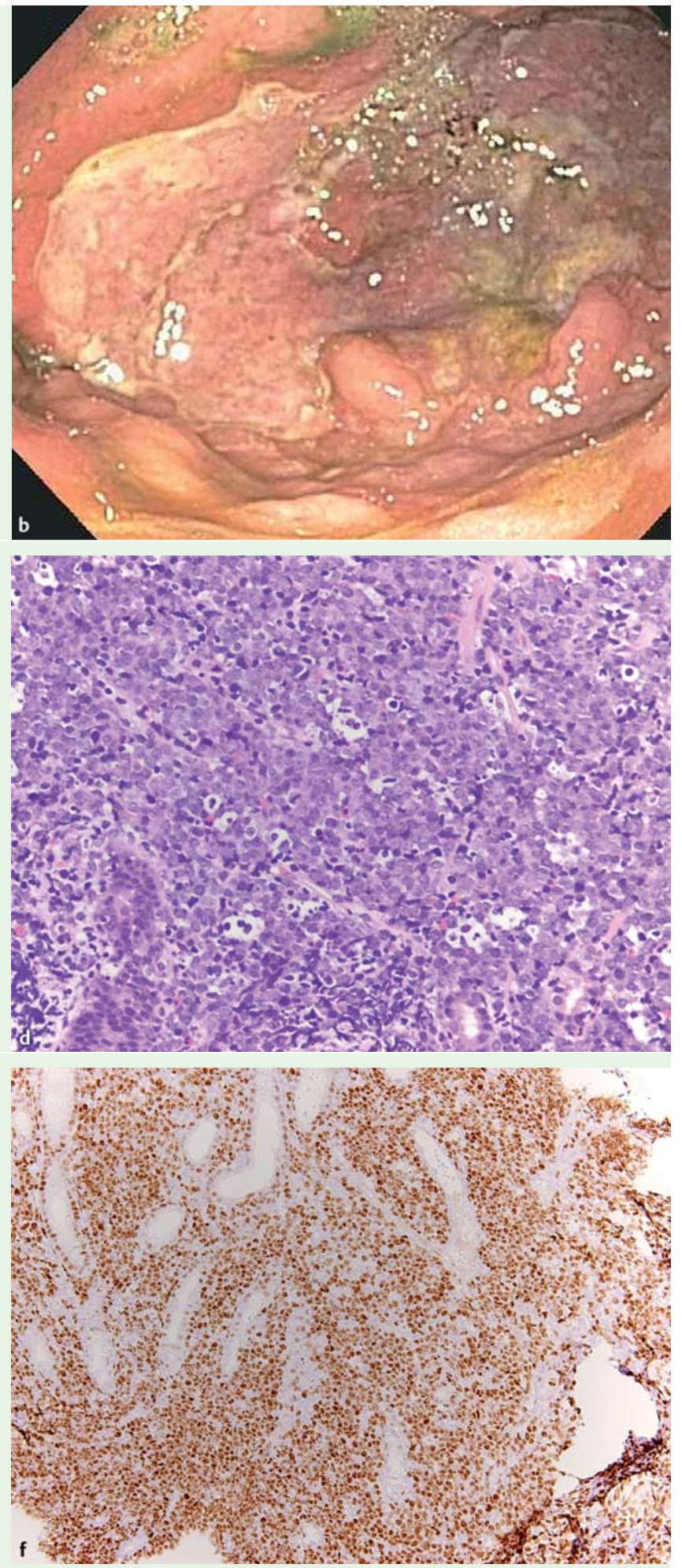

tric wall. $\mathbf{d}-\mathbf{f}$ Histologic features of Burkitt's lymphoma - diffuse proliferation of monotonous lymphocytic cells in the lamina propria of the gastric mucosa with irregular nuclei and abundant mitotic figures (d), and stain positive for BCL-6 (e) and C-MYC (f). 